\title{
Service User Led Organisations in Mental Health Today
}

\section{Abstract}

Background: Since 1990, health policy in England has stressed the importance of user involvement in shaping and delivering services.

Aims: To explore mental health service user-led organisations (ULOs) in England as they interact with decision-makers to bring about change desired by them with a focus is on institutional norms behaviour and specialised knowledge impacting service users' relationships with services.

Method: An ethnography of five ULOs in two provider organisations (NHS Trusts) including observing their meetings and interactions with decision-makers, conducting in-depth interviews and collecting reflective diaries kept by two members of each group.

Results: During the study, one group ceased to operate. This was a group which refused to adopt the institutional rules and norms of managerial discourse. The other four groups survived by navigating the changing environment which existed at the time of the study, although often at some cost. Themes of autonomy and leadership were also identified.

Conclusion: The current environment is one of organisational complexity and change and the place of ULOs is an ambiguous one as they strive to maintain autonomy whilst at the same time being an acceptable voice to managers.

186 words 


\section{Policy background}

It is 25 years since the Griffiths Report ushered in the NHS and Community Care Act (Department of Health 1990) which first enjoined Local Authorities in England to consult with their local publics on their community care plans. Some long-stay institutions for those with mental health conditions still remained open and for that population community care was in its infancy. At the same time the previous decade had seen a burgeoning of local and national organisations of mental health service users, arguably made possible by the closing of institutions which left ex-residents free to organise. These organisations were often vocal and sometimes angry. These organisations in their modern form are the subject of this paper whose purpose is to explore their configurations, successes and frustrations.

The 1990 Act proved a watershed for user involvement as successive administrations incrementally put an emphasis on user and carer involvement in health service design and delivery including in mental health (Department of Health 1999, Department of Health 1999b, NHS Executive 2000). However, there was some ambivalence. In July 1998, the then Secretary of State for Health, Frank Dobson, declared that "community care has failed" leaving vulnerable patients at risk of harm to themselves and others.

The 2010 Coalition government continued to make significant changes in the structure of the NHS with implications for the means by which service users might exercise influence. The 2012 Health Act increased competition between health care providers and increased choice, but it remains unclear what this will entail for users of mental health services, particularly those regarded as needing high intensity care, including in terms of involvement. A White Paper specifically on mental health (Department of Health 2011) focussed on the individual as 'chooser' of services rather than member of the kind of organisation that occupies us here.

\section{Theoretical Frameworks}

\section{A new social movement?}

It has been argued that the emergence of mental health activist groups, at both national and local levels, constitutes a new social movement in the image of Black and women's movements (Menzies, LeFrançois et al. 2013). Whilst patients from other medical specialties 
have organised for improvements in their care and for mutual support (Baggott, Allsop et al. 2005), mental health service user organisations sought wholesale change in services, in their conditions of living and in the way in which 'mental illness' is understood (Barnes and Bowl, 2001). Arguably, such organisations embodied an 'oppositional consciousness' (Mansbridge, 2001) and were a response to what were perceived as injustices rather than solely poor services. Rogers and Pilgrim (1991) argued that mental health service users represent a group ready to form a new social movement because the practices of psychiatry - diagnostic and therapeutic - as well as its coercive possibilities, mark its users off from other medical patients as disempowered or even oppressed. Their analysis conflicts with that of Crossley (2005) who saw a pivotal role for the professionally led anti-psychiatry movement in seeking change.

Crossley has been criticised both from 'within' the movement and by other academic writers. The Survivors History Group (The Survivors History Group 2012) emphasises the grassroots nature of the movement with ex-patients organising for and by themselves. The importance of emotions motivating collective action in response to injustices is also highlighted, but this can cause frustration in encounters with official discourse and bureaucracy (Barnes 2008). Writing in Canada, Church identifies the way in which officials discounted the expression of emotions in official forums as 'bad manners'(Church 1996). This takes an extreme form in cases where such expressions may be pathologised as the return of symptoms of mental illness (Gummer and Furney 1998).

This paper reports on part of a larger study looking in detail at the functioning of ULOs in England in a contemporary context(Rose, Barnes et al. 2014). The particular questions we ask here are: how do members of ULOs manage the institutional norms and rules of behaviour and communication required if they are to be stakeholders in institutional change and what are the relations between knowledge specific to ULOs and organisational knowledge?

Almost all the literature that examines the relationship between managers and other decision makers and ULOs studies the two groups separately (Munn-Giddings, Boyce et al. 2009). Our study of five ULOs included observations of their meetings with managers and 
their own reflections on these in the form of diaries. In this way, we hoped to capture the dynamic of interactions and identify in vivo which behaviours and modes of action facilitated progress and what impeded it. Whilst earlier work could counterpose the views of decision makers and those of service users gathered separately, here we bring them together in order to shed light on our two questions of norms of behaviour and forms of knowledge.

\section{Methods}

\section{Setting}

The study took place in two NHS Foundation Trusts (mental health providers). One was metropolitan and one largely rural. The metropolitan Trust (Trust A) served a younger, more deprived and ethnically diverse population. The rural Trust (Trust B) encompassed two counties and a large urban area and faced challenges relating to the size and spread of population. Average attendance at the groups varied between 10 and 25 .

\section{Design}

This was an exploratory, multiple case study design (Yin 2003) within a specific ethnographic framework.

\section{Sample}

We sought to study two ULOs per Trust - one long standing and 'traditional', and one with a more specific brief such as a focus on a particular activity or a particular group of service users. In practice in the metropolitan Trust we studied three groups because another group approached us to be part of the study.

\section{Data Collection}

Data were collected for one year for each group between 2012 and 2013.Researchers attended group meetings and took notes. We studied the ULOs 'in action' as they interacted both amongst themselves and with purchasers and providers. We asked each group to identify a key goal that involved organisational change and invited two members in each group to keep reflective diaries and record critical events. Towards the end of the 
ethnography, researchers undertook follow-up interviews with key informants. These interviews were digitally recorded and transcribed.

\section{Data Analysis}

Using observation, fieldwork notes, reflective diaries and interviews allowed the triangulation of data and also ensured that data were grounded in the experiences, reflections and perceptions of the participants. Interviews were analysed using a thematic approach (Braun and Clarke 2006) supported by the qualitative software Nvivo9 (Nvivo9 2010). Interpretations of meetings relied on field notes which were analysed using ethnographic principles of 'thick description' and interpretation (Geertz 1973, Hammersley and Atkinson 1989, Savage 2000) made possible by the combination of data collection methods described above. Quotations can be found in Table 1.

\section{Researchers and reflexivity}

The Principal Investigator and some ethnographers were service user researchers with some experience in ULOs. This 'insider knowledge' is unusual in research in this field. Research meetings allowed this knowledge to be deployed but also balanced when reflected upon by other members of the team (Reeves, Kuper et al. 2008).

\section{Ethical approval}

The study received Research Ethics Approval: 11/LO/0584

\section{Results}

\section{The ULOs}

To preserve anonymity, the groups have been named as follows:

Trust A Traditional Group - Metro group

Trust A Specific Group - Arts Group

Trust A Specific Group - Identity Group

Trust B Traditional Group - County group 
Trust B Specific Group - Research Group

\section{Trust A - Traditional Group - Metro}

\section{Autonomy and survival}

One of the selected ULOs, Metro, ceased to operate near the end of the research period. This was one of the 'traditional' groups. Indeed, it was a branch of a host organisation that had enjoyed quite a reputation in the national user movement and had much success in campaigning in the past.

Metro had set itself a goal to improve communication with key decision-makers. The group met monthly with group members only attending the first half of the meeting and professionals and managers attending the second half. We also observed three meetings between group representatives and decision makers and collected the reflections of a diary keeper. In the three meetings between representatives of Metro and managers it became clear that the latter found the group meetings difficult. Adjectives such as "challenging" and "confrontational" were used and, in terms of the goal, it was clear that communication started from a low base.

Difficulties were also experienced by group members who complained about "jargon" and queries about documents being met with referral to other documents.

These reflections pertain to what was said above about autonomy and also about emotion. Metro prized its autonomy and did not wish to adopt corporate language. This was evident within meetings with managers when the latter asked for more 'formal' information, for example monitoring data, and representatives of the ULO responded "but we know from experience". Thus Metro members contested the forms of knowledge valued by managers. In addition, in the group meetings many members were forthright, outspoken and angry.

At an organisational level, it was repeatedly said by managers that Metro should form alliances with other groups, including the 'in-house' Trust user group. It was also suggested that the local user experience survey was more informative than the 'anecdotal' experiences and complaints brought by the ULO members and that these should be made 'official', perhaps by putting them on the appropriate forms. But numbers were exactly 
what Metro did not wish to provide because they believed they knew better than managers what was happening in local services, prizing experiential over formal knowledge. Further, becoming embedded or more linked up with other organisations risked compromising the group, and as one diary keeper put it: "I worry that we will become marginalised".

\section{Trust A - Specific Group - Arts}

\section{The significance of leadership styles and organisational complexity}

One specific ULO was an arts and creativity based organisation which was effectively a userled service providing workshops and other activities to mental health service users in two localities in Trust A.

The CEO emerged in our ethnography as the vital figure in the organisation. She was very experienced in user involvement activities and had been CEO for many years. She was observed to adopt corporate language and to comply with other institutional rules and norms in her conversations with decision makers. She was seen to constantly highlight possible opportunities for the group when conducting specific negotiations and even to make use of the presence of the ethnographer in meetings in a strategic fashion. There was none of the difficulty with language, emotions and behaviour described in the first case study and indeed in interview she appeared to genuinely like the managers she interacted with describing them as "quite straightforward". Observations showed that managers were sympathetic to the CEO's concerns regarding how cuts were affecting mental health service users and there was an element of mutual frustration.

The CEO played a strategic card in another way. In talking to the ethnographer she was at pains to show how, as a ULO, her group had intimate knowledge of service users' needs, aspirations and capacities which stemmed precisely from them being run by service users. However, in her interactions with managers she did not refer to her organisation as user-led showing that she tailored the knowledge she used to different contexts. Further, she positioned herself as an on-the-ground worker who had similar experience to any frontline worker in the Trust. She used the stories of people who used her services to make her points but was not observed to use her own story. In this way, she finessed the very division between managers and service users that was emphasised in the first case study. 


\section{Trust B - Traditional Group - County \\ Working with complex structures}

The third ULO considered is a traditional one with a long history of involvement in a rural setting. It acts to ensure service user involvement in the commissioning, planning and delivery of mental health service users in one of the counties in the Trust and is also involved in training and research. Like the Arts example, however, the CEO of this organisation emerged as a key figure during the ethnography. She has been active in the group since its inception in 1997.

The local Trust was engaged in a reconfiguration of services at the time of our research and the goal set by the ULO was to make this reconfiguration as 'user friendly' as it could be. The ULO decided the best vehicle for this would be a committee comprised of commissioners, service users, carers, GPs and advocacy organisations. This committee was chaired by the CEO of the ULO and its primary function was to enable users of mental health services to engage with Commissioners at a strategic level. The Committee was selected as a vehicle for pursuing the goal in the belief that this would be a powerful body, offering potential for service users to have influence. Selecting this committee meant adopting a tacit agreement to behave in line with institutional managerial norms. However, from the start one commissioner queried the appropriateness of the forum as a site to ensure user involvement (as well as the presence of the ethnographer) on the grounds that the service reconfiguration would have to be implemented by the Trust and so the ULO should be dealing with them. However, the Trust did not involve the ULO in its deliberations regarding the service reconfiguration, preferring to relate to the local Patient Advice and Liaison Service (PALS). The ULO was ultimately successful in getting a senior Trust manager to attend a Commissioning committee. The Trust Manager then invited the ULO Chair to meet with him resulting in the ULO achieving representation on the Trust body concerned with the implementation of the new service.

Once again, the CEO of this ULO positioned herself as having special intelligence in the sense of knowing what was happening on the ground. She was also aware of more general feelings on the part of service users that communication with the Trust could be improved in respect to the service reconfiguration. She rejected the argument that a particular forum 
should not be attended because it was mainly of interest to staff and concerned with the internal workings of the Trust. It is noteworthy that the CEO made use of long standing relationships she had formed in the past. In particular, she was used to working with the senior manager in the Trust responsible for the service reconfiguration and made use of that relationship at a one-to-one level to progress her goals. On the other hand, there were clear tensions in the relationships between the ULO and the local advice and complaints service especially around channels of communication between Trust management and service users over the new service configuration.

The members of this ULO were working in a context of extreme organisational complexity and change. The CEO described herself as "tired and worn". Providers and commissioners perhaps do not appreciate the toll involvement work can take in such complex contexts.

\section{Trust A - Specific Group - Identity \\ Partial autonomy and leadership}

This ULO represented a minority group which traditionally has been badly served by mental health services. It was a small group, again with a strong leader with many years experience in the user movement. Her experience had taught her to be mindful of the need to be democratic and draw other members of the group into all discussions and decisions. Our observations showed this was not always easy.

This ULO set out to secure funding for a development worker. A funding bid was prepared for the local Trust's charitable arm. However, it became clear that some aspects of the bid were beyond the resources of a small group to handle, and so an alliance was formed with a large voluntary sector organisation representing the minority population. At the close of the ethnography funding had been secured and the development worker was in post. However, the process was not smooth.

The leader of the ULO was clear from the start that the group needed to retain its autonomy. In particular, she did not want the development worker to be based in the Trust or have any line management accountability to the Trust. Her view was that in-house user involvement in the Trust was dominated by "white upper class" people who would not understand the specific issues facing this group. Other group members agreed with this. 
However, there was a question of where the development worker, as a paid employee who needed to be on a payroll, could be based.

The larger Non Governmental Organisation (NGO) agreed to help and to host the development worker if the bid was successful although it had little experience with mental health issues or organisations. The Trust eventually did approve the funding and the ethnography then moved to observing the recruitment process. There was a flurry of acrimonious emails, which the ethnographers were copied into, between representatives of the ULO and the Director of the NGO on the subject of the job description and who would manage the worker. The ULO members were worried that the worker would be "taken over" by an organisation which knew nothing about mental health. As we have seen repeatedly, they referred to their specialised knowledge but this time in relation to a third sector organisation. An example was the group's desire to have a worker independent of mental health services whilst the NGO believed a mental health professional would have more authority. In terms of negotiating style, the ULO leader and another prominent member tended to use very lively language in their emails whilst the Director of the NGO was more measured. Again we see a counterpoint between institutional discourse and ULOs pushing the boundaries of acceptable language and behaviour. However, ultimately a compromise was reached and the leader of the ULO accepted that having the NGO on board meant they now had more 'clout'.

\section{Trust B - Specific Group - Research}

\section{Inside out / outside in}

The final group was focussed on research and was part of the Trust's research governance process. The group was established to advise the Trust's research governance bodies on service user involvement and fulfil the role of a critical friend, combining different kinds of expertise to contribute to the methodological refinement, quality and impact of research. The person whom the Trust employed to develop service user involvement in research established the ULO and, at the time of our study, was its Chair.

Interpersonal relationships were critical to the success of the group. Both diary keepers (including the ULO chair) had a long standing and positive relationship with the Director of 
Research. He helped to navigate many of the issues that arose with other Trust staff and during the research period was generally facilitative.

Being an employee of the Trust meant that the ULO chair was familiar with organisational rules and practices and with the general culture of the Trust. She was observed to be confident in negotiating with senior staff and to know her way around departmental procedures. She made full use of her good relationship with the Director. However, she wished the ULO to retain a degree of autonomy and appreciated that her dual role made this difficult. The second diary keeper echoed many of our other groups in stating that she would not become involved in any other user involvement activity in the Trust because it was 'tokenistic'. She believed the chair of the ULO did it "properly".

The strong relationship between the ULO chair and the Director of Research meant that conversations and negotiations between them were usually smooth and conducted with frankness. Although in meetings the chair was observed to be quite challenging she constantly stressed that this was in the spirit of 'critical friendship'. What was less evident was the capacity of such exchanges to achieve broader objectives relating to the influence of service users in relation to Trust research activity.

\section{Discussion}

\section{Autonomy, knowledge and institutional norms}

The theme of autonomy was identified for all the groups. Our two questions regarding corporate behaviour and specialised knowledge were intertwined. All the ULOs wished to retain some degree of autonomy and uniformly based this on their specialised, experiential knowledge of mental health conditions and services. Metro was the most extreme in voicing their own special knowledge, but the others, in different ways and different contexts, concurred. However, the groups other than Metro sought to negotiate this knowledge and its consequences through establishing positive relationships with providers and managers to some degree. Metro's robust approach was its undoing and their frustrations most explicitly stemmed from their refusals to conform to institutional norms of behaviour, eschew emotion and to rely on their membership's direct experience of services. All the groups departed in some degree from what institutional norms dictate negotiating change should 
look like (Barnes 2008) but only Metro did this to such a degree that its position became untenable in a context in which 'user involvement' had become an official practice.

The idea that service users are 'experts by experience' is not new, emerging first in the field of user research (Sweeney, Beresford et al. 2009) but is now commonplace. It is absent in the earlier literature we reviewed but would now seem to be the hallmark of service user involvement as a new social movement. Metro pushed it to the edge but the other groups deployed this perspective strategically. Evidence of two forms of knowledge in the field of mental health - expert and experiential - is strongly present in our data, as are the complexities of negotiating the two.

\section{Leadership}

At least three leaders of ULOs in our ethnography - Arts Group, County Group and Identity Group - were longstanding user movement activists. These leaders emerged as key figures and they had clearly adapted. This raises the age-old question of their 'representativeness' which term is often used as critique (Rose, Fleischmann et al. 2002). In what sense are they reflective of 'ordinary' mental health service users? But do they need to be? Like other experts they have lived a process of the unfolding of a social movement, they have been part of a collective endeavour and been shaped by it. It would be wrong to see them as exceptional 'individuals'; they have been socially formed. This formation was evident in their current activities especially around autonomy but also in lessons that had taught them pragmatism. They embodied dual identities of leader and service user that sometimes caused them personal strain.

\section{Complexity and Change}

The different places where service users might intervene and influence are now immense and diverse. They are also confusing in terms of where efforts might be best placed to effect change in a direction desired by service users. Our study took place in turbulent times for the NHS and social care and the ULOs were constantly adapting to this. Adaptations formed no pattern but seemed to respond to local circumstance. For example, Research Group's success may have depended on both the presence of a champion and encouragement of user involvement in mental health research nationally. Arts Group was struggling with the 
closure of local Day Services, sensing that they were picking up the pieces. The picture is one of ULOs in 'response-mode' which is a departure from the past and may threaten autonomy.

\section{Limitation}

We studied only five groups. Had the number been greater other themes might have been identified. However, the extent of continuity with previous literature and the consistency across groups of new themes suggests that our findings have some generalisability.

\section{Conclusion}

The user movement in mental health services has a long history and our ethnography demonstrates some continuity with themes present since the 1980s. At the same time, the organisational context has undergone, and continues to undergo, huge changes and the user movement, as an integral part of these organisations, has had to adapt to survive. The fate of ULOs is not yet decided. What we can say is that user involvement in mental health is no longer separate organisationally but is part of the landscape and itself influences organisational change. 


\section{References}

Baggott, R., J. Allsop and K. Jones (2005). Speaking for patients and carers: Health consumer groups and the policy process, Palgrave Macmillan Basingstoke.

Barnes, M. (2008). "Passionate participation: Emotional experiences and expressions in deliberative forums." Critical Social Policy 28(4): 461-481.

Braun, V. and V. Clarke (2006). "Using thematic analysis in psychology." Qualitative research in psychology 3(2): 77-101.

Church, K. (1996). "Beyond "Bad Manners": The Power Relations of "Consumer Participation" in Ontario's Community Mental Heath System." Canadian Journal of Community Mental Health 15(2): 27-44.

Department of Health (1990). NHS and Community Care Act, The Stationary Office London. Department of Health (1999). National service framework for mental health, The Stationery Office London.

Department of Health (1999b). Modernising mental health services Safe, sound and supportive, The Stationery Office London.

Department of Health (2011). No health without mental health: A cross-government mental health outcomes strategy for people of all ages, HM Government.

Geertz, C. (1973). Thick Description: Towards an Interpretive Theory of Culture. In (eds) . . The interpretation of Cultures: Selected essays. C. Geertz. New York, Basic Books: 3-30.

Gummer, T. and S. Furney (1998). "The business of listening." Health Management 2: 12-13. Hammersley, M. and P. Atkinson (1989). Ethnography: Principles in practice, Routledge.

Menzies, R. J., B. A. LeFrançois and G. Reaume (2013). Mad Matters: A Critical Reader in Canadian Mad Studies, Canadian Scholars Press.

Munn-Giddings, C., M. Boyce, L. Smith and S. Campbell (2009). "The innovative role of user-led organisations." A Life in the Day 13(3): 14-20.

NHS Executive (2000). The NHS Plan: a plan for investment, a plan for reform. London, Department of Health.

Nvivo9 (2010). QSR Melbourne, QSR.

Reeves, S., A. Kuper and B. D. Hodges (2008). "Qualitative research methodologies: ethnography." Bmj 337.

Rose, D., M. Barnes, M. Crawford, E. Omeni, D. MacDonald and A. Wilson (2014). "How do managers and leaders in the National Health Service and social care respond to service user involvement in mental health services in both its traditional and emergent forms? The ENSUE study." Health Services and Delivery Research 2(10).

Rose, D., P. Fleischmann, F. Tonkiss, P. Campbell and T. Wykes (2002). "User and carer involvement in change management in a mental health context: Review of the literature." Report to the National Co-ordinating Centre for NHS Service Delivery and Organization R \& D. London: Service User

Research Enterprise, Institute of Psychiatry, De Crespigny Park. Savage, J. (2000). "Ethnography and health care." BMJ: British Medical Journal 321(7273): 1400.

Sweeney, A., P. Beresford, A. Faulkner, M. Nettle and D. Rose (2009). This is survivor research, PCCS Books.

The Survivors History Group (2012). The survivors history group takes a critical look at historians. Critical Perspectives on User Involvement. P. M Barnes and M. Cotterell. Bristol, Policy Press. Yin, R. K. (2003). Case study research: Design and methods, SAGE Publications, Incorporated. 